\title{
Teaching and Learning Science: a Dialectic and Complex Relationship
}

\author{
Maria Cecília de Souza Minayo \\ Vice-presidência de Ambiente Comunicação e Informação-Fiocruz, Av. Brasil 4365, 21045-900 Rio de Janeiro, \\ RJ, Brasil
}

Key words: education for science - science and technology - education and health

The debate upon teaching in general and especially about teaching science is always welcome and important and it always leaves those who start it with that feeling of something unfinished. There is no doubt that the feeling is real, mainly in academic fora, because the immeasurable distance between the progress obtained in the scientific field in general and the stagnation or the slow steps given in the area of teaching and learning is also real. Some experts believe that the methods, the techniques and the philosophy used to teach science in the 19th century are valid to the present date. Very little research is made about the art of teaching science and that little very seldom is turned into practice. Maybe it is due to the distance between theories and the daily routine of the classrooms and labs, or maybe it is due to the very well disseminated belief among scientists that those who know the subject know how to teach the subject.

Regarding this topic, I will only make two observations that I believe will add to what has been presented at the round-table. The first one is centered around this fundamental question: "What do we intend, when we introduce someone into the world of science?" Do we expect to stimulate that person to become a specialized researcher or do we also expect a promise of a wise scientist? In view of this dilemma, I would say that the first alternative does not include the second, but the second one does encompass the first one. That is, a scientist (not a simple researcher) is a human being who pays attention to reality, who takes philosophy and arts into consideration, who moves within the concept of ethics and who is capable of offering his/her contribution to society, in the broader context of the world of life. This does not mean that he/she knows beforehand weather his/

Fax: +55-21-270.2496

E-mail: mcmina@netra.castelo.fiocruz.br

Received 7 August 2000

Accepted 4 September 2000 her contribution will be successful or possibly insignificant. It is true that this definition cannot be the curriculum of a post-graduation program in science, yet it is its base and its north. It is not in vain that the title granted to those graduated from the highest academic level is that of philosophy doctor $(\mathrm{PhD})$, which therefore means the (always provisional) crowning of a dynamic process of formation, which contemplates an active intellectual in the world of his/her times.

The second observation is a consequence of the first one. If it is true that the curriculum issue is crucial for the quality of training, it is even more important to include it in an ever more interactive and dynamic view of knowledge production and of its application. The Master's and PhD students have to be prepared to generate, to enhance, to dominate and to use scientific knowledge and technologies, with the purpose of producing goods and services with quality, which meet the health needs of the population. Thus, it is paramount to invest in a praxis, which always incorporates reviews of the contents and methods, adjusting them to the historic changes. The best training is not that which offers more content, so that the student can learn a bit of almost everything and everything about almost nothing. The best training is that which combines disciplinary formation, cultural formation and the specific needs of each student. This means to deregulate the excesses and to try to stimulate creativity as much as possible.

Maybe the most important methodological change needed to face the scientific and technologic progress and to avoid obsolescence is (a) to invest in learning how to learn; emphasizing active learning geared towards problem solving and experimenting of new methodologies; (b) while it is paramount to provide an academic environment which is necessarily critical and pluralist (participation in seminars, congresses, stimulation of reading habits, systematic updating of the bibliography in the area, training on how to write papers, discussions on ethics, politics and philosophy mainly those which affect the sector - and reflection about tradition and innovation; (c) and finally, 
the opportunity to become familiar with the systems of information, communications and informatics.

In the whole world, mainly in the nations where science and technology are highly developed, today we can observe that the high positions in the State, as well as in private corporations, are occupied more and more by $\mathrm{PhDs}$, that is, by people who have had a high level scientific training in their formation. Even in Brazil, mainly at the top-level positions of the government and also in a minor scale, in private business, this is also taking place. It is interesting to observe that these $\mathrm{PhD}$ level professionals usually have positions outside of their area of origin. Therefore, in the most advanced formation environments a debate is held about the need to prepare the students to "face" this extra challenge. That is, such confirmation fortifies the idea of the need to invest to in a specific formation and also in general culture. The training centers should select and provide the items that make-up said culture and, moreover, they should stimulate the search for them. It is absolutely relevant that these centers create opportunities to discuss their own role, if they intend to be more than "factories of researchers".

In 1991, in one of its headers, the Science magazine warned about the need to overcome segmented knowledge (favored by the teaching method based on projects), and to search for new ways to teach and to learn about these phenomena, their implications and applicability; in order to develop a humanistic view, to invest in informatics and in mastering the languages required to participate in the international debate of each specific area of knowledge; and also to develop a management and undertaking capacity. This last point is linked to studies carried out in the United States about the prominence of the PhD level professionals occu- pying top-level command positions in the public and private sectors, as it has already been mentioned.

In order to conclude, it is important to emphasize that techno science is in the core of the changes that are taking place in the world, as the most important productive force in the century that has just ended. Yet, at the same time, it is the producer, the product and the object of this dynamic. It is demanded by the competitive forces of the market and also by the currents of social movements in their search for justice and social welfare. Therefore, it is important to develop a critical and optimistic view of the potentialities of the intellectual world. In the specific case of health, scientific progress has started to create new ideological patterns and life styles influenced by the concept of preventive purification, which was brought up by the development of biology and genetics. The ideas of environmental pureness extracted from ecological theories, the ever more established belief in high-tech medical practices and the valorization of the body and of health through sports, through the cult of physical exercises and through the powerful industry of esthetics and rejuvenation. All these contrast with the frequent persistence or the worsening and reemergence of endemic diseases and epidemics, which are usually linked to underdevelopment and to social inequality. The formation of health professionals takes place within this technical-scientific-communicational environment, which is also highly dynamic, contradictory and pluralist, which contains changing concepts of time and space, combines the universal and the specific in the presence of the issues linked to the intense incorporation of technology and health problems related to poverty, misery and exclusion. There is no way to focus, all one can do is make things more complex! 